\title{
Motor Cortex Excitability Reflects the Subjective Value of Reward and Mediates Its Effects on Incentive-Motivated Performance
}

\author{
Joseph K. Galaro, ${ }^{1}$ PPablo Celnik, ${ }^{2}$ and $\odot$ Vikram S. Chib ${ }^{1,3}$ \\ ${ }^{1}$ Department of Biomedical Engineering, Johns Hopkins School of Medicine, Baltimore, Maryland 21205, 2Department of Physical Medicine \\ and Rehabilitation, Johns Hopkins School of Medicine, Baltimore, Maryland 21287, and ${ }^{3}$ Kennedy Krieger Institute, Baltimore, Maryland 21205
}

Performance-based incentives tend to increase an individual's motivation, resulting in enhancements in behavioral output. While much work has focused on understanding how the brain's reward circuitry influences incentive-motivated performance, fewer studies have investigated how such reward representations act on the motor system. Here we measured motor cortical excitability with transcranial magnetic stimulation while female and male human participants performed a motoric incentive motivation task for prospective monetary gains and losses. We found that individuals' performance increased for increasing prospective gains and losses. While motor cortical excitability appeared insensitive to prospective loss, temporal features of motor cortical excitability for prospective gains were modulated by an independent measure of an individual's subjective preferences for incentive (i.e., loss aversion). Those individuals that were more loss averse had a greater motor cortical sensitivity to prospective gain, closer to movement onset. Critically, behavioral sensitivity to incentive and motor cortical sensitivity to prospective gains were both predicted by loss aversion. Furthermore, causal modeling indicated that motor cortical sensitivity to incentive mediated the relationship between subjective preferences for incentive and behavioral sensitivity to incentive. Together, our findings suggest that motor cortical activity integrates information about the subjective value of reward to invigorate incentive-motivated performance.

Key words: incentive; motivation; motor excitability; transcranial magnetic stimulation

Significance Statement

Increasing incentives tend to increase motivation and effort. Using a motoric incentive motivation task and transcranial magnetic stimulation, we studied the motor cortical mechanisms responsible for incentive-motivated motor performance. We provide experimental evidence that motor cortical sensitivity to incentive mediates the relationship between subjective preferences for incentive and incentive-motivated performance. These results indicate that, rather than simply being a reflection of motor output, motor cortical physiology integrates information about reward value to motivate performance.

\section{Introduction}

We modulate our performance according to the rewards at stake. Larger stakes tend to increase motivation, which in turn elicits increased behavioral output (i.e., increased force exertion) (Pessiglione et al., 2007; Kurniawan et al., 2010; Schmidt et al., 2012);

Received May 8, 2018; revised Nov. 30, 2018; accepted Dec. 4, 2018.

Author contributions: J.K.G. and V.S.C. wrote the first draft of the paper; J.K.G., P.C., and V.S.C. edited the paper; J.K.G., P.C., and V.S.C. designed research; J.K.G. performed research; J.K.G. and V.S.C. contributed unpublished reagents/analytic tools; J.K.G. analyzed data; J.K.G. and V.S.C. wrote the paper.

This work was supported by the Eunice Kennedy Shriver National Institute of Child Health \& Human Development, National Institutes of Health Award K12HD073945 to V.S.C. J.K.G. was supported by the National Defense Science and Engineering Graduate Fellowship. We thank Firas Mawase for insightful comments.

The authors declare no competing financial interests.

Correspondence should be addressed to Vikram S. Chib at vchib@jhu.edu.

https://doi.org/10.1523/JNEUROSCI.1254-18.2018

Copyright $\odot 2019$ the authors $\quad 0270-6474 / 19 / 391236-13 \$ 15.00 / 0$ and increased success rate during a skilled motor task (Chib et al., 2012, 2014). Incentive motivation refers to the processes that convert higher reward expectancies into increased performance (Berridge, 2004). These processes include forming a subjective representation of prospective reward, which invigorates behavioral performance. The effects of incentive motivation on effortful exertion has been the topic of extensive investigation in psychology (Bolles, 1972; Bindra, 1974; Bolles and Fanselow, 1980), and in more recent years, the field of cognitive neuroscience has begun to dissect how the brain's reward circuity influences motivated performance (Pessiglione et al., 2007; Talmi et al., 2008; Chib et al., 2012; Schmidt et al., 2012). However, motivated performance is not only related to processing the rewards at stake, but also how these reward representations influence activity in motor cortex to result in behavioral performance. Despite 
the neural crosstalk between motivation and motor processing during incentivized performance (Mogenson et al., 1980; Bray et al., 2008; Talmi et al., 2008; Chib et al., 2014), the understanding of how motor cortical excitability gives rise to incentive-motivated performance is fairly limited.

Transcranial magnetic stimulation (TMS) provides precise timing to study how motor cortical excitability is influenced by motivating stimuli. Freeman et al. (2014) recently used TMS to demonstrate that stimuli predicting an appetitive juice reward (i.e., conditioned stimulus), paired with an instrumental response in extinction (i.e., performance was not reward-contingent), served to increase motor cortical excitability and responding; whereas stimuli predicting the absence of reward did not invoke increases in motor excitability. In a follow-up study, they found that presentation of aversive stimuli inhibited motor evoked potentials (MEPs) during trials that did not require instrumental responding (i.e., no-go trials) (Chiu et al., 2014). Together, these results illustrate that motivational information spills into the motor system, influencing motor cortical excitability before execution.

Studies of binary choice have also used TMS to study the dynamics of motor excitability before action selection. This work has shown that motor cortical activity builds in the time period before a choice cue is presented and that excitability increases as a function of the value of the chosen option (Duque and Ivry, 2009; Klein et al., 2012; Klein-Flügge et al., 2013). From these results, it has been suggested that action selection during choice entails a competition, within motor-related areas, in which motor cortical excitability integrates reward value to drive a motor response. Furthermore, it was found that during binary choice of risky options, motor excitability was best described by chosen and unchosen subjective value (i.e., accounting for prospect theoretic measures) (Klein-Flügge and Bestmann, 2012). These studies suggest that the dynamics of motor excitability captures the value of reward during simple choice. However, it is not known how subjective preferences for incentives might influence motor cortical excitability to drive incentive-motivated performance.

The aim of this study was to investigate the role of motor cortical excitability on incentive motivation, and how these cortical processes interact with representations of subjective value to result in motivated performance. We hypothesized that the sensitivity of motor excitability to incentive would be predictive of an individual's motivated performance. This hypothesis has its basis in previous TMS studies that found that motor cortical excitability, measured before instrumental responding, was modulated in response to conditioned stimuli that previously predicted appetitive and aversive outcomes (Chiu et al., 2014; Freeman et al., 2014; Freeman and Aron, 2016). We also hypothesized that motor cortical excitability would be related to an independent behavioral measure of subjective preferences for incentive. This hypothesis has its basis in previous TMS studies, which found that motor cortical excitability reflected subjective chosen and unchosen values during binary choice (Klein-Flügge and Bestmann, 2012); and neuroimaging studies, which found that the functional connectivity between reward regions and motor cortex, during instrumental responding for reward, was modulated by behavioral measures of subjective preferences (Chib et al., 2012, 2014). Specifically, our previous behavioral and neuroimaging studies (Chib et al., 2012, 2014) found that incentives associated with successful task performance are initially encoded as a potential gain and, when actually performing a task, individuals encode the potential loss that would arise from failure. Given these findings, we predicted that subjective feelings of loss, in- stantiated by a measure of loss aversion, would be predictive of incentive-motivated performance and motor cortical excitability.

\section{Materials and Methods}

\section{Experimental design and statistical analyses}

All participants were right-handed and prescreened to exclude those with a prior history of neurological or psychiatric illness. The Johns Hopkins Medical Institute Institutional Review Board approved this study, and all participants gave informed consent. Using an effect size from our previous study examining the relationship between incentive-motivated performance and neural sensitivity to value ( $r=0.70,95 \%$ CI $[0.40,0.88])$ (Chib et al., 2012), a significance of $<0.05$ with a power goal of at least 0.80 , a power analysis indicated that we would need at least 13 subjects to reproduce this effect. We aimed to collect data from 20 participants, to account for the possibility of attrition, exclusion due to lack of task compliance, or misestimation of the subjective reward preference data. In the end, 19 participants (mean age, 20 years; age range, 18-23 years; 12 females, 7 males) were recruited and took part in the experiment. Each participant performed the motor task and a behavioral choice paradigm to characterize subjective preferences for incentive (i.e., loss aversion and risk aversion). One participant was excluded from the final analysis because of atypical choices during the subjective reward preference task (i.e., rejection of all gambles with potential losses).

All analyses were conducted in MATLAB 2018a (MathWorks), with the exception of the hierarchal Bayesian modeling for subjective reward preference analysis (described below). Hierarchical linear models were implemented to test population-level effects on subject-level estimates, implemented in Matlab using fitglme, with no covariance matrix restrictions. Analyses that examined population-level exertion report effects of slope on subject-level z-scored mean force exertion. Analyses that examined the subpopulation motor cortical findings used ANOVAs of hierarchical linear models to evaluate the two-way interaction of timing and reward subjectivity. Subject-level parameters were estimated from generalized linear models (GLMs) (described below), implemented in Matlab using fitglm. Correlations were reported with Pearson coefficients and $95 \%$ confidence intervals (CIs) generated by 10,000 iteration bootstrapping. Additionally, standardized regressions were used for the mediation analysis, and the completely standardized indirect effect size was bootstrapped to measure mediation (Preacher and Kelley, 2011).

\section{Experimental setup and brain stimulation}

Participants sat in a chair and held a force transducer (LMD300, FUTEK) between the thumb and forefinger of their right hand. During the experiment, participants rested their head in a custom-built gantry. The gantry minimized head-movements across trials and ensured accurate brain stimulator placement. An armrest ensured consistent positioning of the arm across trials. Visual stimuli were presented using MATLAB 2014a and Psychtoolbox-3 (Brainard, 1997; Kleiner et al., 2007).

To record MEPs elicited from TMS, surface electromyographic electrodes were placed on the first dorsal interosseous (FDI) muscle; and these signals were recorded, amplified, and filtered (Bortec Biomedical). To elicit MEPs, we delivered TMS using a $70 \mathrm{~mm}$ figure-eight coil (Magstim) to the optimal scalp position over the left motor cortex. To ensure accurate and precise placement of the TMS coil throughout the experiment, we used a frameless neuronavigation system (Brainsight, Rouge Research) and coregistered participants' heads to a default Talairach template provided in the Brainsight software suite. The coil was placed tangentially on the scalp with the handle pointing backward and laterally at a 45 degree angle away from the midline, perpendicular to the central sulcus.

We first coregistered participants' heads to a standard magnetic resonance image in the neuronavigation system. Then we identified the optimal area for eliciting MEPs in the resting FDI. The optimal M1 location was defined as the site in which we could elicit a localized motor response at a minimal intensity. At this location, we determined the resting motor threshold, defined as the minimum TMS intensity that evoked an MEP of $50 \mu \mathrm{V}$ in 5 of 10 trials in the FDI of the right hand (Pascual-Leone et al., 1994; Rossini et al., 1994). A deviation of $>3 \mathrm{~mm}$ or 15 degrees resulted in the experimenter repositioning the coil during the intertrial interval 
and trials with subthreshold MEP magnitude were excluded from analysis.

The stimulation timings presented in this experiment (50 and $150 \mathrm{~ms}$ ) were informed by a number of previous studies that examined how motor cortical excitability evolves in the time period between presentation of a 'Go' cue and movement, and were chosen to probe the early and late stages of motor preparation (Chen and Hallett, 1999; Leocani et al., 2000; Duque and Ivry, 2009; Klein-Flügge and Bestmann, 2012; Hortobágyi et al., 2017). Specifically, our stimulation times were meant to capture motor cortical excitability in the first half of reaction time (because reaction times are usually in range of 200-300 ms), while minimizing the influence of motor cortical stimulation on performance (e.g., motor quickening). We focused on two stimulation times to ensure we sampled enough trials at each incentive level and stimulation time to maximize the possibility of obtaining behavioral and motor cortical effects. Similar variably timed, single pulse TMS paradigms have been used to study the neural processing of different types of affective processes (Pitcher et al., 2007, 2012; Klein-Flügge and Bestmann, 2012; Klein-Flügge et al., 2013).

To control between participants and conditions, the stimulus intensity was calibrated on a per subject basis during the calibration phase. For this procedure, TMS pulse intensity was adjusted such that pulses delivered $50 \mathrm{~ms}$ following the 'Go' cue elicited a $1 \mathrm{mV}$ MEP. The stimulation intensity was fixed to this value for the remainder of the experiment (i.e., the same intensity was used on 50 and $150 \mathrm{~ms}$ trials during familiarization and incentivized phases, described below). This procedure was similar to those previously used to study motor cortical excitability (Stefan et al., 2004; Vallence et al., 2013). To generate this baseline MEP level, the first 30 trials of the unincentivized phase (described below) involved only TMS pulses $50 \mathrm{~ms}$ following the 'Go' cue and the experimenter monitored the elicited MEPs to target $1 \mathrm{mV}$. Additionally, the initial stimulator intensity was set to $120 \%$ of a participant's resting motor threshold.

\section{Motor task}

Participants first performed a calibration phase to determine their maximum voluntary contraction (MVC) during an isometric pinch grip. This involved participants maintaining their maximum pinch exertion for $4 \mathrm{~s}$, on 3 consecutive trials, each separated by a $5 \mathrm{~s}$ rest period. MVC was calculated as the maximum pinch force exerted on the 3 calibration trials. Because we acquired each individual's MVC, we were able to standardize difficulty, based on MVC ability, across participants.

The main experiment was divided into two phases: unincentivized and incentivized (Fig. 1). During both phases of the experiment, participants performed an isometric pinch exertion task. Participants were not instructed to grip on every trial and were free to respond with grip force at their discretion (i.e., they could forgo exerting effort if they were so inclined). This task was chosen because pinch grip isolates use of the FDI muscle, which we targeted in our TMS procedure, to study the relationship between incentive, motor excitability, and performance. TMS was performed on every trial of each phase of the experiment. Participants were instructed that they would receive a show-up fee of $\$ 15$ at the end of experiment in addition to any earnings from their performance in the incentivized phase.

The unincentivized phase was comprised of 60 trials. At the beginning of each trial, participants were presented a blue cursor that moved across the screen in proportion to the amount of pinch exertion (Fig. 1). Squeezing the force transducer moved the cursor horizontally to the left, whereas relaxing caused the cursor to move right. Participants were instructed to place the cursor in the start position $(X)$ for a random amount of time (3-6s). This start position corresponded to minimal pinch exertion while still grasping the force transducer. During the task, a 'Go' cue and a target line registered to $45 \%$ of MVC appeared on the screen. To successfully achieve the task, participants had to exert pinch effort to move the cursor across the target line within $0.5 \mathrm{~s}$. At the end of a trial, participants were shown a message indicating their performance. Following the initial 30 trial TMS calibration epoch (described above), the remaining 30 trials involved TMS delivered at either 50 or $150 \mathrm{~ms}$ after presentation of the 'Go' cue, and visual feedback during exertion was withheld. This trial epoch was meant to familiarize participants with the conditions of the main experimental task. The stimulation times were evenly distributed across trials.

During the incentivized phase, participants performed the isometric pinch exertion task as described above, for varying amounts of monetary gain or loss. We did not present participants with feedback of their hand cursor, or the effort target, to allow them to reach the target effort level under their own implicit motivation. At the beginning of the experiment, participants were given an endowment of $\$ 20$ in cash, separate from their show-up fee, and were told that, at the end of the experiment, one trial would be selected randomly and a payment made according to their performance on that trial. Participants were told that their \$20 endowment was given to them so that they could pay any eventual losses at the end of the experiment. This payout mechanism ensured that trials had significant monetary consequences and that participants evaluated each trial independently. Participants performed trials for a range of incentives (i.e., $\pm \$ 0, \$ 10, \$ 20$ ). Each incentive level was presented randomly 30 times for a total of 180 trials, with an equal balance of conditions for TMS pulse timing (i.e., $50 \mathrm{~ms}$ TMS pulse; $150 \mathrm{~ms}$ TMS pulse). Importantly, $+\$ 0$ and $-\$ 0$ conditions did not differ in their objective value, but only their framing (i.e., "Win $\$ 0$ " and "Lose $\$ 0$ "). At the beginning of each trial, participants were shown a message indicating the amount of incentive for which they were playing. They then performed the motor task, with the same success criteria as during the unincentivized phase. At the end of the experiment, a single trial was selected at random and participants were paid based on their performance on that trial.

To summarize, our task had several important features: (1) During the incentivized performance phase, we did not display cursor position to participants so they could not simply target the necessary effort level. Instead, they exerted effort in accordance with what they remembered the target effort level to be; and because they were not able to see the target, any extra exertion that they produced captured implicit incentive motivational spillover into motor performance. (2) We parametrically modulated incentive to provide a finer grained assessment of how performance varies with incentive, unlike previous investigations of motor cortical influences on instrumental performance, which used appetitive and aversive conditioned stimuli (in extinction) and were not designed to examine parametric effects of rewards (Chiu et al., 2014; Freeman et al., 2014; Freeman and Aron, 2016). Furthermore, these studies did not examine how reward subjectivity influenced motor excitably and performance, rewards were not contingent on performance, and they did not present data that implicated a mechanistic framework by which valuation could influence motivated performance through motor excitability. Notably, the previous TMS studies that did parametrically vary incentive were designed to study decision-making and not reward-contingent incentive-motivated performance (Klein-Flügge and Bestmann, 2012; Klein-Flügge et al., 2013). (3) To evaluate the influence of subjective preferences on incentive motivation, we had participants perform a separate prospect theory task that provided a precise measurement of subjective preferences for incentive (i.e., loss aversion, risk aversion) (Sokol-Hessner et al., 2009; Chib et al., 2012, 2014). This task generated measures of subjective preferences for reward that were independent of the incentive motivation task, which allowed an unbiased means to examine relationships between sensitivity to incentive, incentivemotivated behavior, and motor cortical excitability.

\section{Subjective reward preference task (measurement of loss aversion and risk aversion)}

Participants received an initial endowment of \$25 in cash (this amount was separate from their show-up fee and earnings/endowment from the motor task) and were told that, at the end of the experiment, one trial would be selected randomly and a payment made according to their actual decision during the experiment. Participants were told that their $\$ 25$ endowment was given to them so that they could pay any eventual losses at the end of the experiment. Any amount from the endowment that remained after subtracting a loss was theirs to keep, and similarly any eventual gain earned in the experiment was added to the initial endowment. During the experiment, participants made choices among 140 different pairs of monetary gambles. Each pair contained a certain option 


\section{A}

\section{Unincentivized Phase}

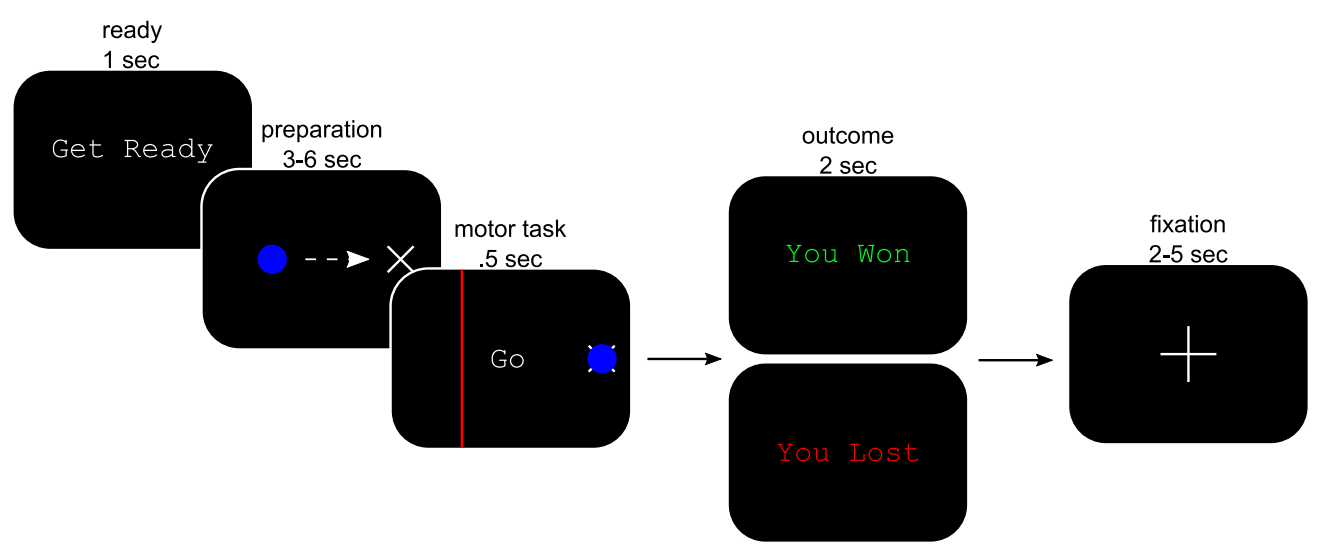

B

\begin{tabular}{|c|c|c|c|c|c|}
\hline \multirow{3}{*}{ Calibration: 30 Trials } & ready & preparation & motor task & outcome & $\begin{array}{l}\text { fixation } \\
2-5 \mathrm{sec}\end{array}$ \\
\hline & & & & & $2-5 \mathrm{sec}$ \\
\hline & & & $\begin{array}{l}\text { stimulation } \\
(50 \mathrm{~ms})\end{array}$ & & \\
\hline \multirow{2}{*}{ Familiarization: 30 Trials } & $\begin{array}{l}\text { ready } \\
1 \mathrm{sec}\end{array}$ & $\begin{array}{l}\text { preparation } \\
3-6 \mathrm{sec}\end{array}$ & $\begin{array}{c}\text { motor task } \\
\text { (no feedback) }\end{array}$ & $\begin{array}{l}\text { outcome } \\
2 \mathrm{sec}\end{array}$ & $\begin{array}{l}\text { fixation } \\
2-5 \mathrm{sec}\end{array}$ \\
\hline & & & $\begin{array}{l}\text { stimulation } \\
\text { (50ms or } 150 \mathrm{~ms})\end{array}$ & & \\
\hline
\end{tabular}

\section{C} Incentivized Phase

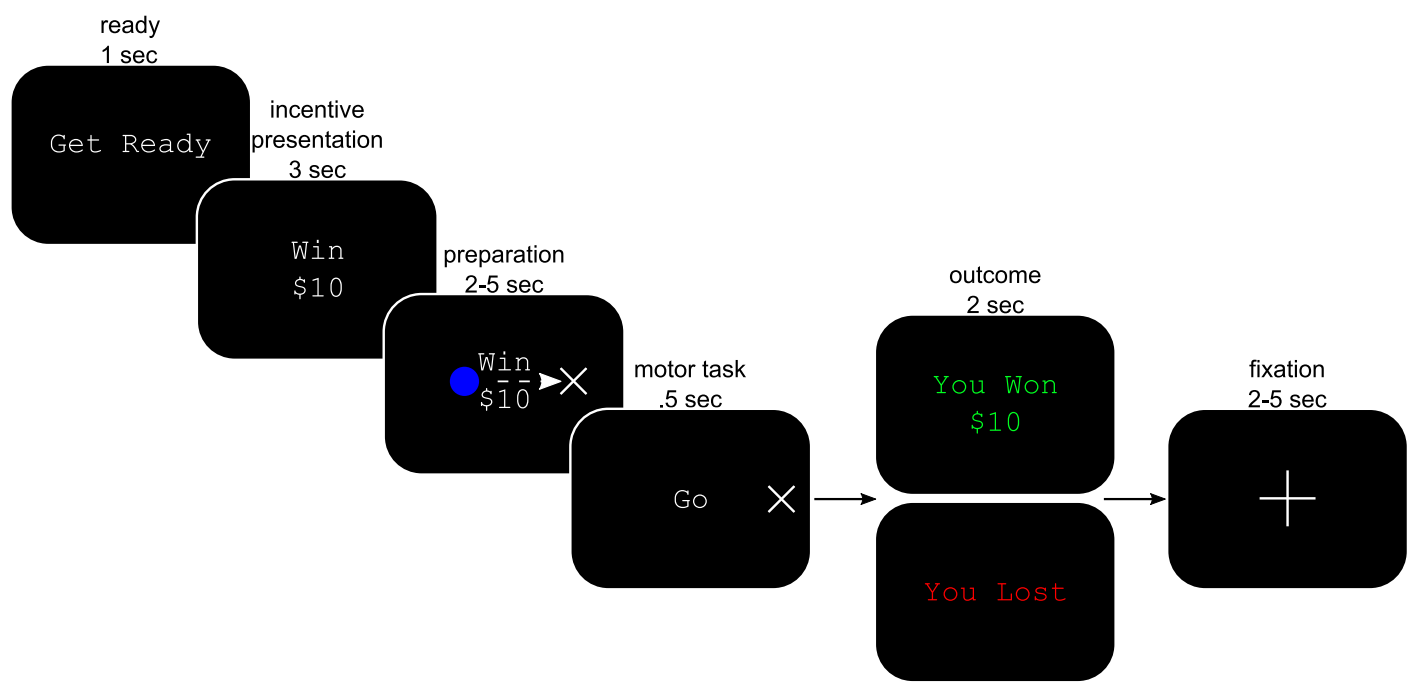

D

\begin{tabular}{|c|c|c|c|c|c|c|}
\hline & $\begin{array}{l}\text { ready } \\
1 \mathrm{sec}\end{array}$ & $\begin{array}{l}\text { incentive } \\
\text { presentation } \\
3 \mathrm{sec}\end{array}$ & $\begin{array}{l}\text { preparation } \\
2-5 \mathrm{sec}\end{array}$ & $\begin{array}{l}\text { motor task } \\
B \measuredangle .5 \mathrm{sec}\end{array}$ & $\begin{array}{l}\text { outcome } \\
2 \mathrm{sec}\end{array}$ & $\begin{array}{l}\text { fixation } \\
2-5 \text { sec }\end{array}$ \\
\hline Incentivized: 180 Irials & & & & $\begin{array}{l}\text { stimulation } \\
(50 \mathrm{~ms} \text { or } 150 \mathrm{~ms})\end{array}$ & & \\
\hline
\end{tabular}

Figure 1. The incentive motivation motor task. $A$, Participants first performed an unincentivized phase of the experiment to calibrate TMS parameters and familiarize them with the requirements of behavioral paradigm. At the beginning of each trial, participants were presented a blue cursor that moved across the screen in proportion to the amount of pinch exertion. Squeezing the force transducer moved the cursor horizontally to the left, whereas relaxing caused the cursor to move to the right. To initiate the task, participants placed the cursor in the start position $(X)$ for a random amount of time (3-6s). The start position corresponded to minimal exertion while still grasping the transducer. During the task, a ' $\mathrm{Go}^{\prime}$ cue and red target line appeared that was registered to $45 \%$ of MVC. To successfully achieve the task, participants had to move their cursor across the target line within $0.5 \mathrm{~s}$. At the end of the trial, they were shown a message indicating the outcome of their performance. In the case that a participant successfully moved the cursor across the target line, a positive message was displayed ("You Won"); otherwise, the participant was informed of the negative outcome ("You Lost"). B, The timeline of unincentivized trials. Participants first performed 30 calibration trials in which stimulation occurred $50 \mathrm{~ms}$ after the onset of the ' $\mathrm{Go}$ ' cue/motor task presentation (calibration). After these trials, familiarization trials were performed in which stimulation was delivered for another 30 trials at either 50 or $150 \mathrm{~ms}$ after ' $G \mathrm{G}^{\prime}$ cue/motor task presentation (familiarization). C, Incentivized trials were identical to the unincentivized trials, except that participants were presented with the incentive they were performing for before the motor task screen, and they were not given feedback of their cursor or the target line. $\boldsymbol{D}$, The timeline of incentivized trials. There were a total of 180 incentivized trials, and stimulation was delivered at either 50 or 150 $\mathrm{ms}$ after ' $G 0^{\prime}$ cue/motor task presentation. 


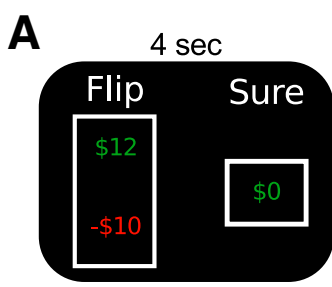

B

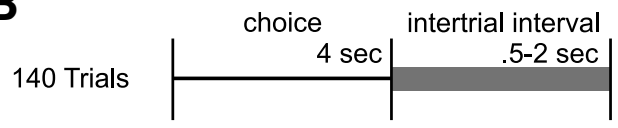

Figure 2. Subjective preference task. $A$, After performing the motor task, participants performed a separate task in which they made a series of forced monetary choices between a risky option ("Flip" option; equal probability of gain and loss) and a guaranteed amount ("Sure" option). $\boldsymbol{B}$, The timeline of the subjective preference task trials.

involving a payout with $100 \%$ probability $S$ and a risky option involving gain $G$ and loss $L$ with equal probability (Fig. 2). Participants had $4 \mathrm{~s}$ to make a choice. The values for gain, loss, and sure options were the same as those used in previous studies that estimated individuals' loss aversion (Sokol-Hessner et al., 2009; Frydman et al., 2011). Specifically, gambles involving a potential gain or loss, and an alternative sure amount of $\$ 0$ were generated from the comprehensive combination of $G \in$ $\{2,4,5,6,8,9,10,12\}$ and $L \in\left[.25^{\star} G, 2^{\star} G\right]$ in multiplier increments of 0.125 . For the options involving a potential gain for an alternative sure amount, the set was as follows:

$(G, S) \in\{(2,1),(3,1),(4,2),(5,2),(7,3),(8,3),(12,6),(12,5)$,

$(12,4),(13,5),(13,6),(19,8),(22,10),(23,10),(25,9)$,

$(25,10),(26,10),(26,12),(28,13),(30,12)\}$.

Data analysis

Behavioral performance analysis. Our main behavioral measure of performance was the mean effort exerted on each trial, defined as mean force exerted between the time the exertion threshold is met (i.e., the first recording $>10 \%$ of MVC after the 'Go' cue) and the end of the trial. We excluded trials if detected reaction time intersected with MEP onset, participants were unable to reach the target within the allotted time, or participants failed to move. We used a GLM with the magnitude of potential gain and loss $x \in\{0,10,20\}$ and valence $v \in\{1,-1\}$ as independent variables, and performance (log transformed mean force to correct for skewness) as the dependent variable as follows:

$$
\log (\text { Mean Force })= \begin{cases}\beta_{\text {Exertion }}^{\text {Gain }} x+C^{\text {Gain }} & \text { if } v=1 \\ \beta_{\text {Exertion }}^{\text {Loss }} x+C^{\text {Loss }} & \text { if } v=-1\end{cases}
$$

The regression coefficients $\beta_{\text {Exertion }}^{\text {Gain }}$ and $\beta_{\text {Exertion }}^{\text {Loss }}$ represent a participant's sensitivity in performance to increasing potential gains and losses: larger $\beta$ parameters correspond to a participant having greater increases in performance as a function of increasing incentives. The parameters $C^{\text {Gain }}$ and $C^{\text {Loss }}$ capture the performance offset associated with each valence condition, equivalent to the behavior at $\$ 0$ incentivization.

Motor cortical excitability analysis. We assessed cortical excitability by measuring the peak-to-peak amplitudes (in $\mathrm{mV}$ ) of the motor evoke potential from the FDI muscle on all stimulation trials. This measure was defined as the MEP. In a similar fashion to the behavioral analysis, we used a GLM to examine the sensitivity of motor cortical excitability to reward, at 50 and $150 \mathrm{~ms}$ following the 'Go' cue. In this model, the magnitude of potential gain and $\operatorname{loss} x$, valence $v$, and stimulation time $t$, were independent variables; and MEP was the dependent variable. We $z$-scored within-session and stimulation condition to account for between-session variability in MEP measurements resulting from factors, such as subject movement, repositioning of TMS coil, etc., during rest periods as follows:

$$
\begin{aligned}
& z \text {-scored (MEP at } 50 \mathrm{~ms})= \begin{cases}\beta_{50}^{\mathrm{Gain}} x+C_{50}^{\mathrm{Gain}} & \text { if } v=1 \\
\beta_{50}^{\mathrm{Loss}} x+C_{50}^{\mathrm{Loss}} & \text { if } v=-1\end{cases} \\
& z \text {-scored (MEP at } 150 \mathrm{~ms})= \begin{cases}\beta_{150}^{\mathrm{Gain}} x+C_{150}^{\text {Gain }} & \text { if } v=1 \\
\beta_{150}^{\text {Loss }} x+C_{150}^{\text {Loss }} & \text { if } v=-1\end{cases}
\end{aligned}
$$

The coefficient terms $\left(\beta_{50}^{\mathrm{Gain}}, \beta_{50}^{\mathrm{Loss}}, \beta_{150}^{\mathrm{Gain}}\right.$, and $\left.\beta_{150}^{\mathrm{Loss}}\right)$ represent an individual's motor cortical sensitivity to incentive at time points following incentive presentation at 50 or $150 \mathrm{~ms}$ after the 'Go' cue. The intercept terms $\left(C_{50}^{\text {Gain }}, C_{50}^{\text {Loss }}, C_{150}^{\text {Gain }}\right.$, and $\left.C_{150}^{\text {Loss }}\right)$ capture the MEP offset associated with each valence condition.

Subjective reward preference analysis. We fit prospect theory-inspired models of the nonlinear processes underlying subjective valuation of reward to participant's choice data from the subjective reward preference task, using a hierarchical Bayesian approach. This model was identical to that used previously (Sokol-Hessner et al., 2009; Chib et al., 2012, 2014), implemented using Monte-Carlo Markov Chain sampling methods provided by rStan version 2.2.0 (Stan Development Team, 2017) in R version 3.0.2 (R Development Core Team, 2008), using the methodology described by the hBayesDM package (Ahn et al., 2017). We expressed participants' utility function $u(x)$ for monetary values $x$ as follows:

$$
u(x \mid \lambda, \rho)= \begin{cases}x^{\rho} & \text { if } x \geq 0 \\ -\lambda(-x)^{\rho} & \text { if } x<0\end{cases}
$$

This formulation is used to compute the utilities of the risky and certain alternative. The model's parameters quantify loss aversion $(\lambda$, the relative multiplicative weight placed on losses compared with gains), risk attitudes ( $\rho$, feelings about chance, or diminishing marginal sensitivity to value). Assuming participants combine probabilities and utilities linearly, the expected utility of a mixed gamble can be written as $U(G, L, S \mid \lambda, \rho)=.5\left(G^{\rho}-\lambda L^{\rho}\right)-S^{\rho}$, where $G$ and $L$ are the respective gain and loss of a presented risky option and $S$ is a fixed alternative choice. The probability that a participant chooses to make a gamble is given by the softmax function as follows:

$$
P(G, L, S \mid \lambda, \rho, \tau)=\frac{1}{1+e^{-\tau^{*} U(G, L, S \mid \lambda, \rho)}}
$$

where $\tau$ is a temperature parameter representing the stochasticity of a participant's choice ( $\tau=0$ means choices are random). This model was fit to the choice data using standard hierarchical Bayesian methods, and applied constraints on the fit parameters such that: $\lambda \in(0,5), \rho \in(0,2)$, and $\tau \in(0,10)$. Weakly informative priors were used on the constrained domain, and a noncentered parametrization was used to facilitate model convergence (Betancourt and Girolami, 2015). All analyses of loss aversion used $\log (\lambda)$; the logarithm is commonly used because $\lambda$ is positively skewed.

Mediation analysis. Mediation analysis is a specific case of structural equation modeling that refers to a situation that includes three or more variables, such that there is a causal process between all three variables (Judd and Kenny, 1981). In a mediation relationship, there is a direct effect between an independent variable and a dependent variable. There are also indirect effects between an independent variable and a mediator variable and between a mediator variable and a dependent variable. This formulation allows for a test of the strength of the direct effect between the independent and dependent variables, accounting for connections via a mediating variable. A measure of the indirect effect (after controlling for the mediator) can be obtained using a series of regressions for all of the causal pathways and estimating the change in the direct effect.

We performed a mediation analysis of our data using standardized linear regression to test the possibility that the relationships between subjective preferences for reward (instantiated by loss aversion), and task performance (performance sensitivity to increasing potential gain) were mediated through motor cortical excitability. For these analyses, we performed between-participant standardized regressions with variables for participants' behavioral loss aversion, the difference in motor cortical sensitivity to prospective gain between stimulation at 50 and $150 \mathrm{~ms}$ $\left(\beta_{150}^{\text {Gain }}-\beta_{50}^{\text {Gain }}\right)$, and the performance sensitivity to increasing potential gain $\left(\beta_{\text {Exertion }}^{\text {Gain }}\right)$. Our main mediation hypothesis was that $\beta_{150}^{\text {Gain }}-\beta_{50}^{\text {Gain }}$ 
mediates the relationship between $\log (\lambda)$ and performance. To rule out model misspecification, we also tested control models in which the causal structure of our experiment was preserved (i.e., motor excitability preceded performance), and alternative relationships were modeled. This included a model in which $\log (\lambda)$ mediated the relationship between $\beta_{150}^{\mathrm{Gain}}-\beta_{50}^{\mathrm{Gain}}$ and $\beta_{\mathrm{Exertion}}^{\mathrm{Gain}}$, and another model in which $\beta_{\text {Exertion }}^{\text {Gain }}$ mediates the relationship between $\beta_{150}^{\text {Gain }}-\beta_{50}^{\text {Gain }}$ and $\log (\lambda)$. We used bootstrapping (a nonparametric sampling procedure) to test whether the specified mediator significantly mediated the relation between the independent and dependent variables (Preacher and Hayes, 2004).

\section{Results}

To test our hypothesis, we developed a task in which participants were instructed to exert pinch grip beyond a predetermined threshold to win or avoid losing monetary incentives ranging from $\$ 0$ to $\$ 20$. We stimulated participants' motor cortex with TMS at two time points, between the presentation of incentive and movement onset, to examine how motor cortical sensitivity to incentive was related to incentive motivation. Participants also performed a separate decision-making task after performing the motor task, in which they made choices over prospective monetary gains and losses. This task allowed us to obtain computational parameters that described each participants' subjective preferences for incentive (i.e., loss aversion and risk aversion).

To foreshadow the results, we found that participants exhibited increasing behavioral performance for increasing incentives, and that these increases in performance were related to motor cortical sensitivity to incentive in the time period between incentive presentation and movement. Both performance and motor cortical sensitivity to incentive were related to measures of participants' loss aversion, such that those individuals that were more loss averse (i.e., had a greater sensitivity to incentive) exhibited larger behavioral and motor cortical sensitivity to incentive. A formal mediation analysis revealed that motor cortical sensitivity to incentive mediated the relationship between subjective preferences for incentive and performance.

\section{Behavioral performance}

As expected, prospective gains and losses led to increases in participants' percent success when comparing $\$ 0$ trials to $\$ 10$ and $\$ 20$ trials (Fig. 3A; Wilcoxon signed rank paired test to account for skewed distribution at $\$ 10$ and $\$ 20$ and including otherwise excluded trials, Gain: $z=2.6, p=0.011$; Loss: $z=2.8, p=$ $0.0048)$. We also observed robust relationships between participants' mean exertion as a function of incentive. We found that participants also exhibited increasing mean exertion, with increasing incentives, in both the gain and loss conditions (Fig. $3 B$; hierarchical linear model; Gain: $\beta=0.018, t_{(104)}=$ $3.8, p=2.6 \times 10^{-4}$; Loss: $\beta=0.025, t_{(104)}=7.0, p=2.9 \times$ $\left.10^{-10}\right)$. Together, these results illustrate that increasing incentives serve to increase behavioral performance in both the gain and loss domain.

We next examined the relationship between participants' behavioral sensitivity to increasing prospective gains and losses in the incentive motivation task (encoded as the slope between mean force exertion and incentive value), and an independent measure of participants' sensitivity to incentive obtained from a separate decision-making task. We reasoned that those individuals that found incentives to be more subjectively valuable (i.e., have a higher loss aversion) would have increased behavioral sensitivity to incentive. We found a significant relationship between participant-specific loss aversion and behavioral sensitivity in the gain domain (Fig. 3C; Pearson correlation, $r=0.58,95 \%$
CI $[0.10,0.87], p=0.011)$; however, we failed to find a significant relationship between these measures in the loss domain (Fig. $3 D$; Pearson correlation, $r=0.16,95 \%$ CI $[-0.17,0.50], p=0.52$ ). This suggests that, for prospective gains, processing of the subjective value of incentive serves to motivate behavioral performance in the incentive motivation task. These results align with our previous work, which found that loss aversion was predictive of increases in performance for incentives in the range tested in this experiment. In those previous studies, we found that worries about loss (instantiated by loss aversion) served to motivate performance for both prospective gains (Chib et al., 2012, 2014) and losses (Chib et al., 2014). Specifically, measures of loss aversion not only predicted performance decrements for large incentives, but also the incentive leading to peak performance for small levels of incentive.

Loss aversion represents a tendency to value losses greater than equal magnitude gains. Risk aversion, on the other hand, is a more general aversion to increased variance in potential gains or losses. To ensure a loss aversion-based hypothesis better accounted for our behavioral data than a general aversion to risk, we also examined the relationship between risk aversion and behavioral sensitivity in the gain and loss domains. We did not find a significant correlation between behavioral sensitivity to incentive and risk preferences (Pearson correlation, Gain: $r=0.12$, 95\% CI $[-0.39,0.60], p=0.63$; Loss: $r=0.19,95 \%$ CI $[-0.26$, $0.56], p=0.46$ ), nor choice stochasticity (Pearson correlation, Gain: $r=0.22,95 \%$ CI $[-0.27,0.73], p=0.39$; Loss: $r=-0.19$, $95 \%$ CI $[-0.53,0.25], p=0.45)$. Furthermore, we failed to find a significant correlation between maximum likelihood estimated loss aversion and either risk aversion or choice stochasticity parameters, suggesting that distinct processes underlie these parameters (correlations with $\log (\lambda),-\log (\rho): r=0.32, p=0.19$; $\log (\tau): r=-0.41, p=0.09)$. We also ran a model comparison of the separately estimated choice parameters and found that $\log (\lambda)$ provided the best description of the behavioral sensitivity to incentive in the gain domain $\left(B I C_{\log (\lambda)}=-150.72 ; B I C_{-\log (\rho)}=\right.$ $\left.-143.46 ; B I C_{\log (\lambda)}=-144.06\right)$. This provides converging evidence that behavioral sensitivity to prospective gains is best described by an independent measure of reward subjectivity characterized by a measure of loss aversion. These findings are consistent with our previous results showing that loss aversion was predictive of behavioral performance during a skilled-motor task for incentive (Chib et al., 2012, 2014).

\section{Motor cortical excitability in response to incentive}

We sought to identify how motor cortical sensitivity to incentive, in the context of the incentive motivation task, was related to subjective preferences for incentive. To this end, we explored parameter estimates from our GLM of motor cortical sensitivity to incentive, separated by participants' behavioral loss aversion (participant specific medial split) (Fig. 4A,B). These parameter estimates capture the slope of the relationship between motor cortical excitability and incentive level. Larger parameter estimates correspond to a more pronounced change in motor cortical excitability in response to increasing incentive.

In the gain domain, we found a significant interaction between stimulation time and loss aversion, indicating that individuals with higher loss aversion had an increased motor cortical sensitivity to incentive, closer to movement onset (Fig. 4A; mixed-effects ANOVA, $\left.F_{(1,32)}=8.0, p=0.0078\right)$. Moreover, we found that this effect was driven by individuals with higher loss aversion having an increased motor cortical sensitivity at the 150 


\section{A}
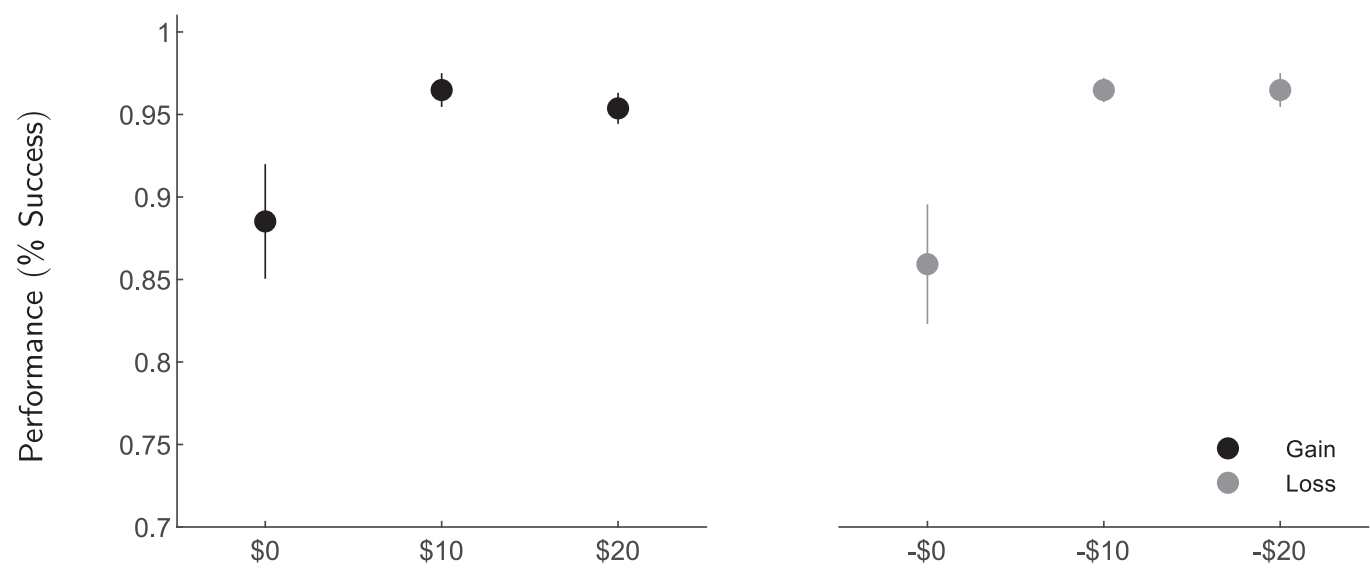

B
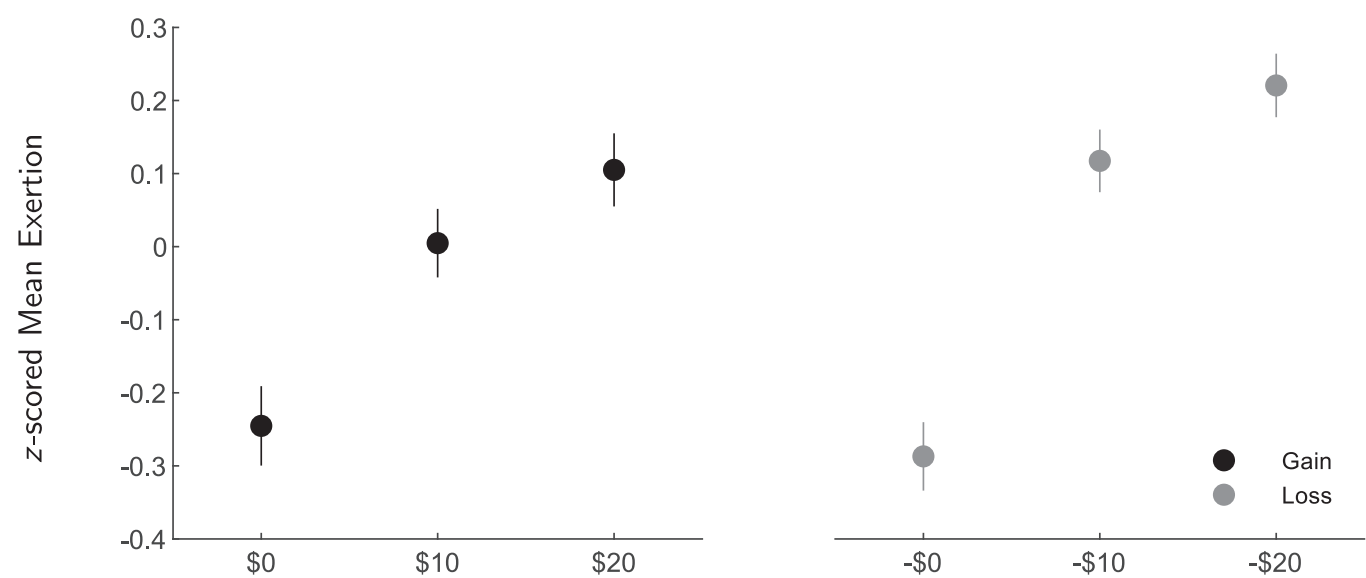

C
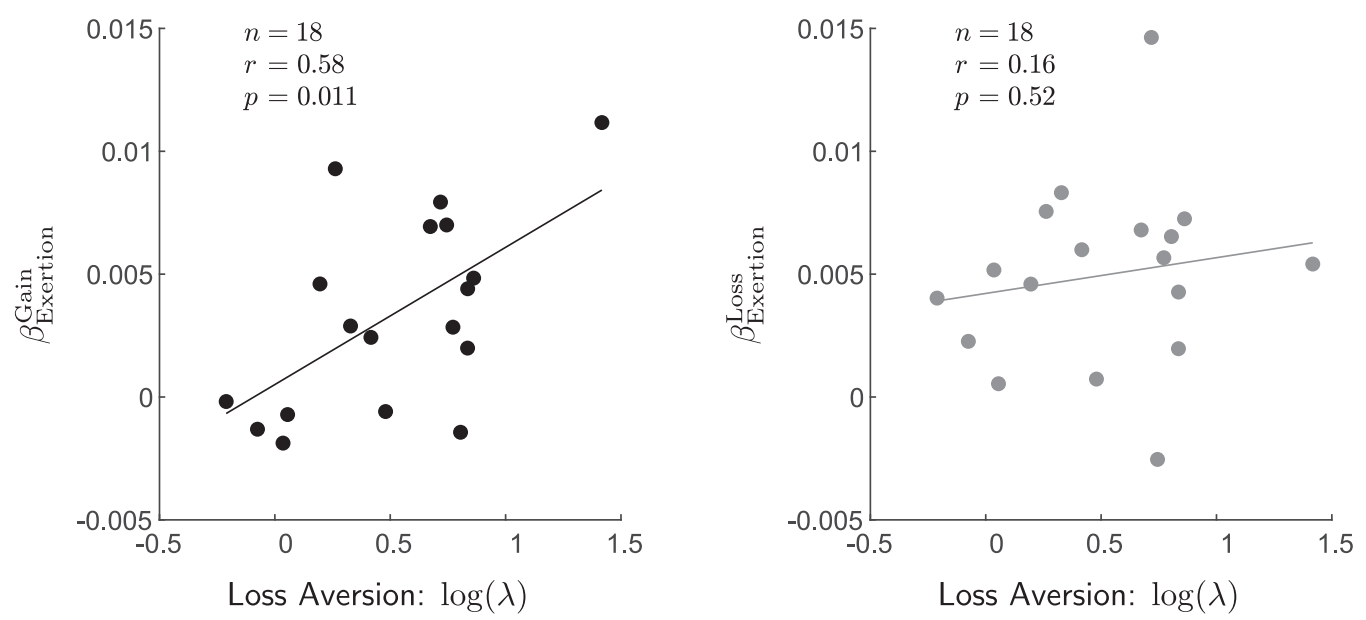

Figure 3. Behavioral results. A, Participants exhibited increasing performance (\% success) for increasing prospective gains and losses. B, Participants exerted more pinch force (mean effort exertion) for increasing prospective gains and losses. Mean exertion was z-scored to control for interparticipant variability in performance. Plots of the correlation between participants' behavioral sensitivity to prospective $(\boldsymbol{C})$ gains and $(\boldsymbol{D})$ losses (i.e., slope of the relationship between un-normalized log mean exertion and incentive) and loss aversion. Error bars indicate SEM.

ms stimulation time point (Fig. $4 A$, post hoc one-tailed Welch's $t$-test, $\left.t_{(10.48)}=3.0, p=0.0059\right)$. In the loss domain, we failed to find a significant interaction between changes in MEP sensitivity between the 50 and 150 stimulation time points and behavioral loss aversion (Fig. 4B; mixed-effects ANOVA, $F_{(1,32)}=0.0093$, $p=0.92)$.

Our paradigm did not elicit correlations between behavioral and motor cortical sensitivity to value in the loss domain. It 
A

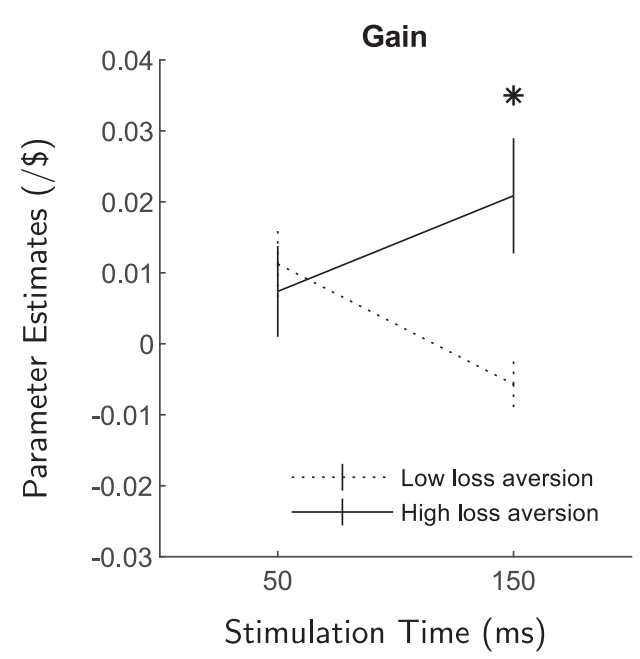

C

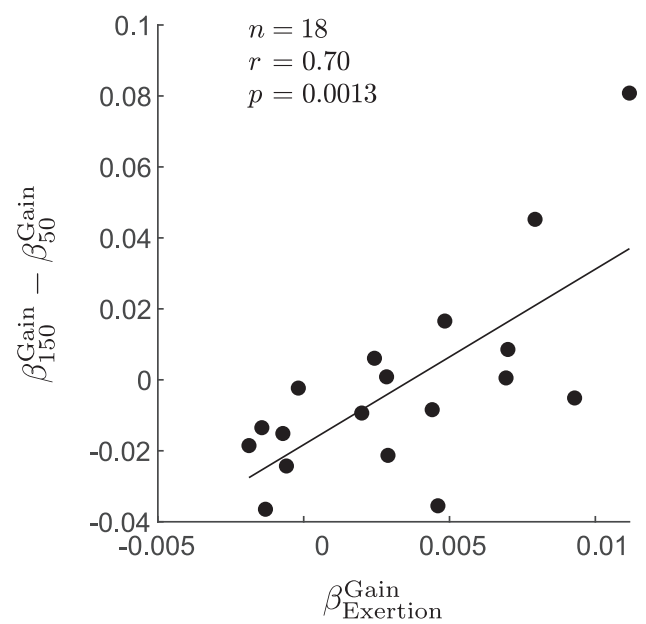

B

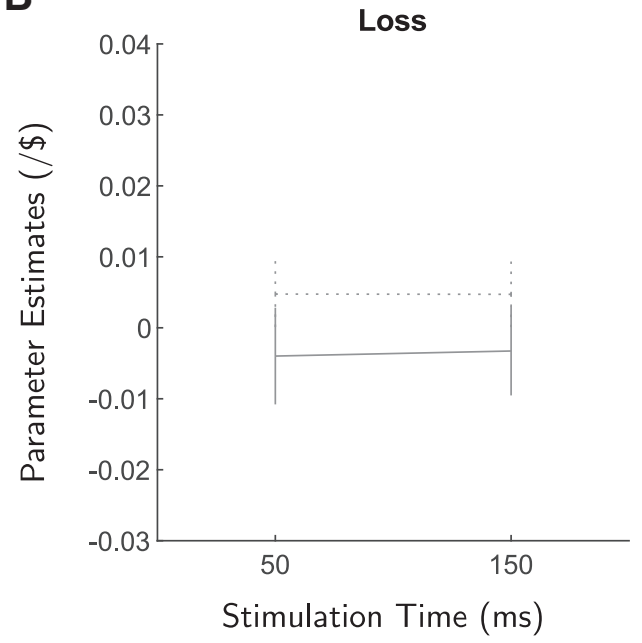

D

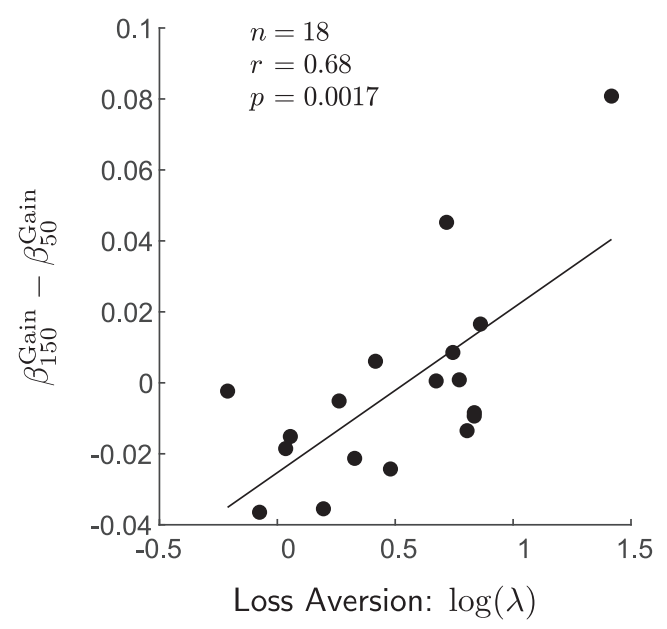

Figure 4. Motor cortical excitability in response to incentive. Shown are parameter estimates from our GLM predicting motor cortical sensitivity to incentive at the different TMS time points. Positive parameter estimates indicate increasing motor excitability with increasing incentive. Negative estimates indicate decreasing motor excitability with increasing incentive. Zero estimates indicate no modulation of motor cortical excitability with incentive. $\boldsymbol{A}, \boldsymbol{B}$, We separated trials based on prospective gain and loss, and grouped participants by the extent of their loss aversion (median split). In the gain domain, we found that those participants that were more loss averse had greater increases in motor cortical excitability in response to incentive, closer to movement onset ( 150 ms). We failed to find significant modulation of motor cortical excitably for prospective loss. The significance levels shown are for planned comparisons between conditions $\left({ }^{*} p<0.05\right)$. Error bars indicate SEM. Plots of the correlations between difference in motor cortical sensitivity to incentive between the 150 and 50 ms stimulation conditions, in the gain domain, and ( $C$ ) behavioral sensitivity to incentive (i.e., slope of the relationship between un-normalized log mean exertion and incentive) and (D) behavioral loss aversion.

should be noted that this null result is consistent with a previous study of motor cortical responses to aversive stimuli, which failed to find a significant change in MEPs, relative to baseline, when individuals were presented an aversive conditioned stimulus paired with an instrumental response (Chiu et al., 2014). With this null result in the loss domain in mind, we focused the remainder of our motor cortical analyses on trials for prospective gain.

To further examine the temporal dynamics of motor cortical sensitivity to incentive over the continuum of loss aversion, we performed a between-participant regression of loss aversion and difference in sensitivity to incentive between the 50 and $150 \mathrm{~ms}$ time points $\beta_{150}^{\mathrm{Gain}}-\beta_{50}^{\mathrm{Gain}}$. The difference between these metrics is an indication of the stability of motor cortical excitably to incentive over time. The greater the difference between these parameter estimates, the more positively correlated to incentive an individual's motor cortical excitably is closer to movement onset. We found that those individuals that were more sensitive to incentive, when comparing 50 and $150 \mathrm{~ms}$ time points, exhibited increased incentive-motivated performance (Fig. 4C; Pearson correlation, $r=0.70,95 \%$ CI $[0.32,0.89], p=0.0013)$. We also performed a regression between participant-specific loss aversion and sensitivity to incentive between the 50 and $150 \mathrm{~ms}$ time points and found that individuals with higher loss aversion exhibited increased changes in motor cortical sensitivity closer to movement onset (Fig. 4D; Pearson correlation, $r=0.68$, 95\% CI [0.29, 0.88], $p=0.0017)$.

In keeping with our incentive motivation hypotheses of motor cortical activity, these relationships suggest that, in the gain domain, subjective preferences for incentive (instantiated by individuals' loss aversion) could serve to amplify motor cortical sensitivity to incentive and energize motor performance.

We performed a series of analyses to ensure that the TMS incentive effects that we observed were not simply the byproduct of confounds between stimulation timing and movement execution. Premovement motor cortical stimulation is known to elicit movement quickening, in which stimulations delivered closer to 


\section{A}

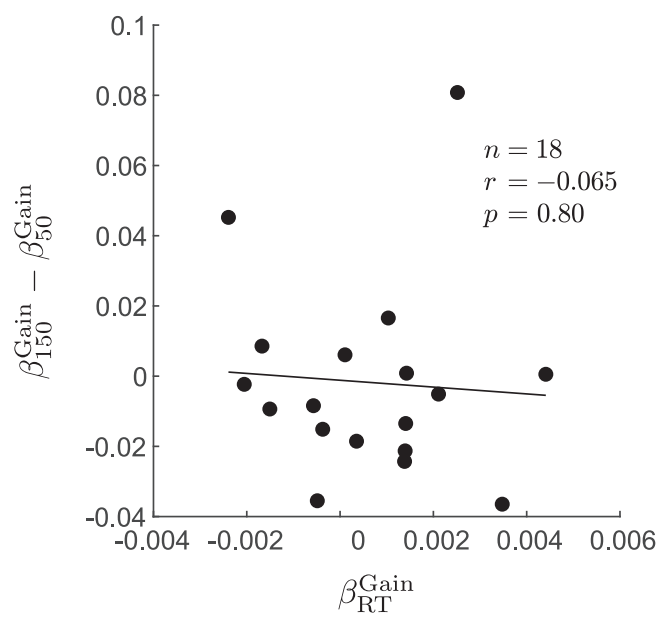

C

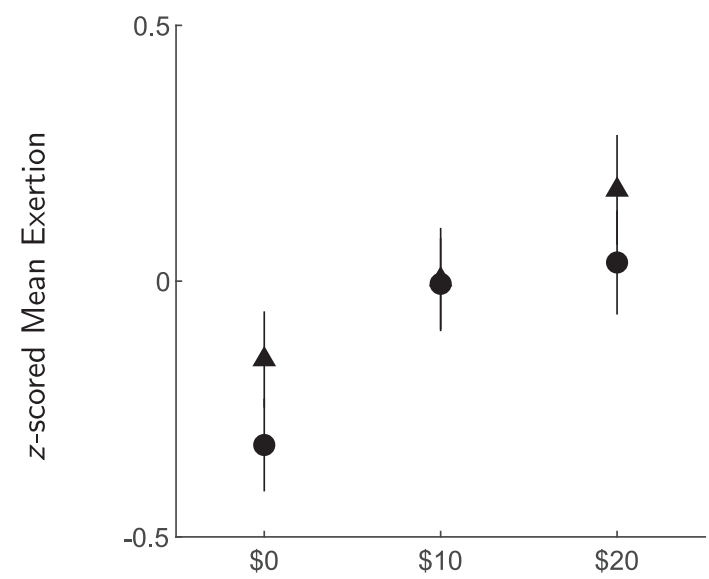

B

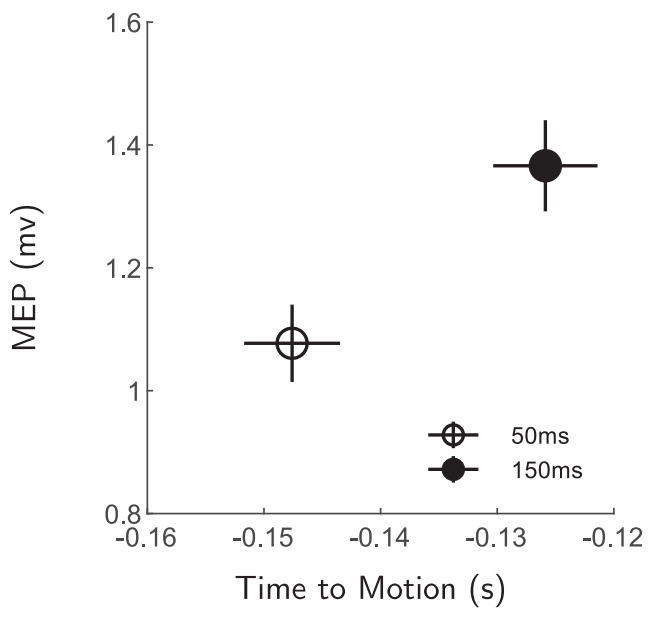

Figure 5. Control TMS analyses. $A$, We did not find a significant relationship between difference in motor cortical sensitivity to incentive between 50 and $150 \mathrm{~ms}$ and reaction time sensitivity to incentive. $\boldsymbol{B}, \mathrm{MEP}$ s were segregated in intensity and time when aligning them to EMG detected movement onset, rather than the ' $G 0^{\prime}$ ' cue. $\boldsymbol{C}$, Participants' $z$-scored mean exertion was separated by stimulation timing conditions. The behavioral finding of increased performance with increasing incentive was preserved across stimulation conditions. Error bars indicate SEM.

movement onset decrease reaction time. To ensure that our TMS incentive effects were not simply the byproduct of a quickening response, we examined the relationship between log reaction time sensitivity to incentive (i.e., the regression coefficient between log reaction time and incentive) and motor cortical sensitivity to incentive, at each stimulation time point, using the measure $\beta_{150}^{\text {Gain }}-\beta_{50}^{\text {Gain }}$. We failed to find a significant correlation between these measures, suggesting that our effects were not simply the results of TMS quickening movements as a function of incentive (Fig. 5A; Pearson correlation, $r=-0.065$, 95\% CI $[-0.67,0.41], p=0.80)$.

Another possible confounding factor in our motor cortical data could be that participants initiate their movements based on the auditory cue of TMS pulses, rather than the 'Go' cue. This would result in no segregation between motor cortical activity between the 50 and $150 \mathrm{~ms}$ stimulation conditions, making it difficult to distinguish the temporal features of motor cortical sensitivity to incentive. To determine whether our data were confounded in this way, we evaluated motor cortical excitability using a model in which trials were separated based on the eventual time of movement onset (as identified from participants EMG data using AGLRStep) (Staude et al., 2001), rather than presentation of the 'Go' cue (as in our main experimental results). We found that, although there was some quickening as a result of
TMS (i.e., MEPs were not separated by a full $100 \mathrm{~ms}$ ), MEPs occurred at significantly different time points relative to movement onset (Fig. $5 B$; paired $t$-test, $t_{(17)}=15.4, p=2.0 \times 10^{-11}$ ). Moreover, we found that MEPs were larger in the $150 \mathrm{~ms}$ stimulation condition compared with the $50 \mathrm{~ms}$ condition (Fig. $5 B$; paired $t$-test, $t_{(17)}=4.7, p=2.3 \times 10^{-4}$ ), consistent with previous studies that have shown increasing motor cortical excitability approaching movement onset (Chen and Hallett, 1999).

To rule out the possibility that our behavioral effects were simply the byproduct of motor cortical stimulation, we first examined the interaction between incentive and stimulation time by partitioning trials between the 50 and $150 \mathrm{~ms}$ stimulation conditions. Our behavioral finding of increased performance with increasing incentive was preserved in both the gain and loss conditions (Fig. 5C; hierarchical linear model interaction term, Gain: $\beta=-0.001, t_{(208)}=-0.20, p=0.85$; Loss: $\beta=0.009$, $\left.t_{(208)}=1.5, p=0.15\right)$. This suggests that our behavioral effects were not simply the result of stimulation timing. Second, while we found increasing behavioral performance in both the loss and gain conditions (Fig. $3 A, B$ ), we found that prospective gains resulted in a modulation of motor cortical excitability (Fig. $4 A$ ), whereas prospective losses did not (Fig. 4B). Together, these results suggest that our behavioral and stimulation effects were specifically the result of the presentation of prospective gains, and 
A

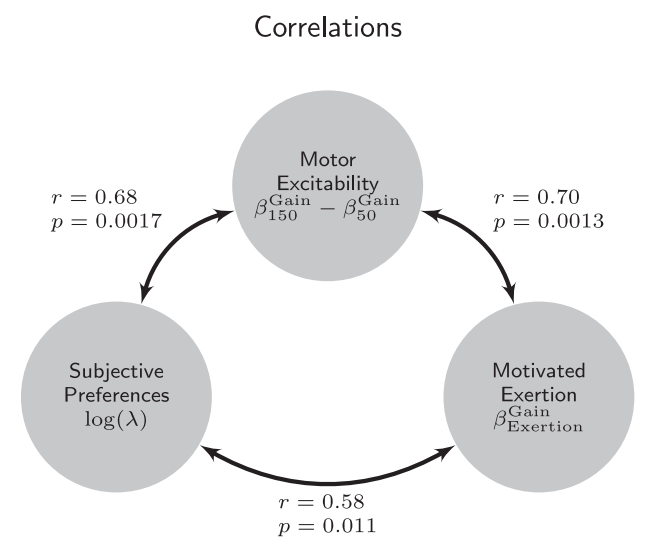

C

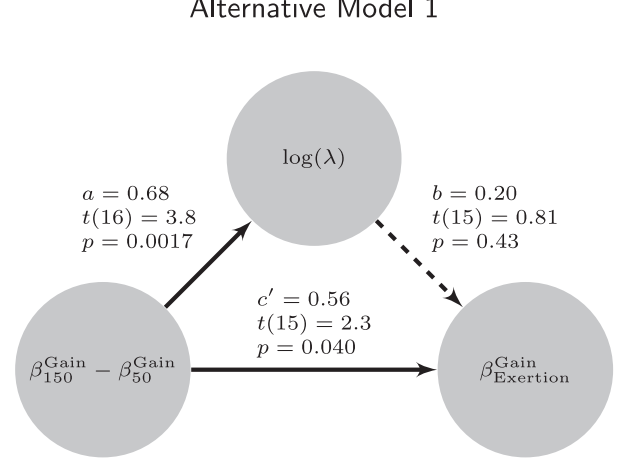

B

Causal Model

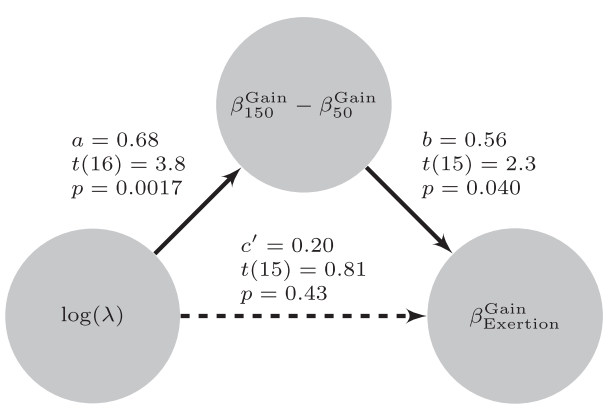

D

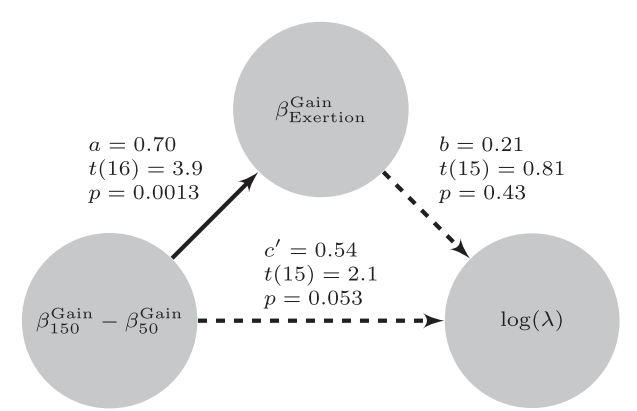

Figure 6. Mediation analyses. $\boldsymbol{A}$, The three variables assessed using mediation analysis: behavioral loss aversion $\log (\lambda)$ difference in motor cortical sensitivity to incentive between the 50 and 150

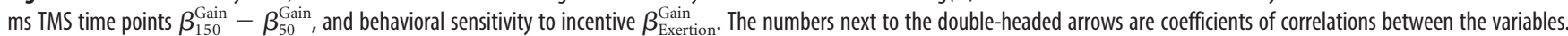
Regression analyses (illustrated in Figs. $3 C, 4 C, D)$ established correlations between participants' behavioral loss aversion, differences in motor cortical sensitivity to incentive, and behavioral sensitivity to incentive. $\boldsymbol{B}$, The causal model illustrates the mediation analysis. $\boldsymbol{C}, \boldsymbol{D}$, The alternative models illustrate control models that were tested to rule out model misspecification. Solid arrows indicate significant relationships between variables. Dashed arrows are not significant.

not simply the result of a general influence of brain stimulation on motor performance or motor cortical excitability.

\section{Causal influences of loss aversion and motor cortical excitability on incentive motivation}

Because loss aversion and behavioral sensitivity to incentive are correlated, and both of these variables are correlated with the temporal evolution of motor cortical sensitivity to incentive (Fig. $6 A$ ), we investigated the hypothesis that motor cortical sensitivity to incentive has a causal influence on loss aversion-related incentive-motivated exertion. To test this hypothesis, we used mediation analysis, a form of linear modeling in which correlations observed in the data are explained by assuming that a specific set of causal influences exist among the variables (Judd and Kenny, 1981). This analysis alone does not establish causality but identifies whether a causal hypothesis is best fit for the data. We fit a model to the data that followed the logical progression of our experimental paradigm. In this model, we assumed that behavioral loss aversion influenced incentive-motivated exertion and that the temporal dynamics of motor cortical sensitivity to incentive (the mediating variable) influenced incentive-motivated exertion.

In our causal model (Fig. 6B), behavioral loss aversion had a significant effect on the difference in motor cortical sensitivity to incentive between the 50 and $150 \mathrm{~ms}$ time points (standardized linear regression, $\left.\beta=0.68, t_{(16)}=3.8, p=0.0017\right)$. When behavioral loss aversion and this measure of motor cortical sensitivity to incentive were simultaneously modeled as predictors of per- formance, loss aversion no longer significantly predicted performance (standardized linear regression, $\beta=0.20, t_{(15)}=0.81, p=$ 0.43 ), whereas motor cortical sensitivity to incentive remained significant in the model (standardized linear regression, $\beta=$ $0.56, t_{(15)}=2.3, p=0.040$ ). This reduction in the direct relationship between loss aversion and incentive motivation was significant (standardized indirect effect size, $a b=0.38,95 \%$ CI [0.047, $0.80], p<0.05$, as tested by a bootstrapping procedure based on 10,000 resamples). This model provides causal support for the idea that manifestations of subjective preferences for incentive motivate incentivized performance through the influence of the temporal dynamics of motor cortical sensitivity on motor performance. Alternative models (Fig. 6C,D) ruled out model misspecification and did not find significant mediation effects by loss aversion $(95 \%$ CI $[-0.28,0.50], p \geq 0.05)$ or performance $(95 \%$ CI $[-0.23,0.68], p \geq 0.05)$.

We explored additional alternative models to test whether the temporal dynamics of motor cortical sensitivity to incentive partially mediated the relationship between either risk aversion (Fig. $7 A$ ) or choice stochasticity (Fig. $7 B$ ) and incentive-motivated exertion. These alternative models did not contain the significant correlations required to test whether motor cortical sensitivity to incentive mediated the relationship between performance and other subjective reward valuation parameters. These results lend further support to the specificity of loss aversion to predict relationships between behavioral performance and motor cortical activity. 
A

Risk Aversion Correlations

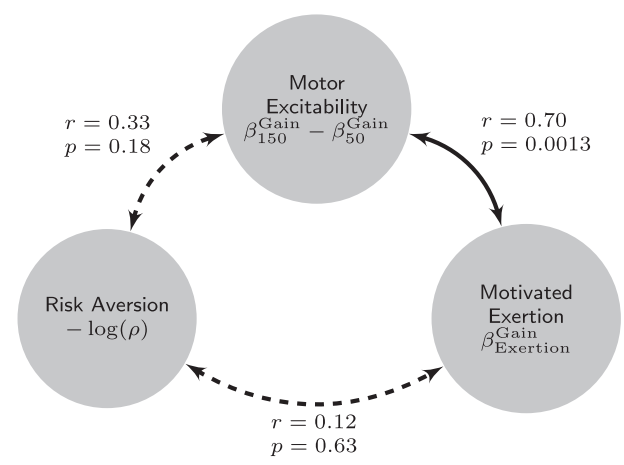

B

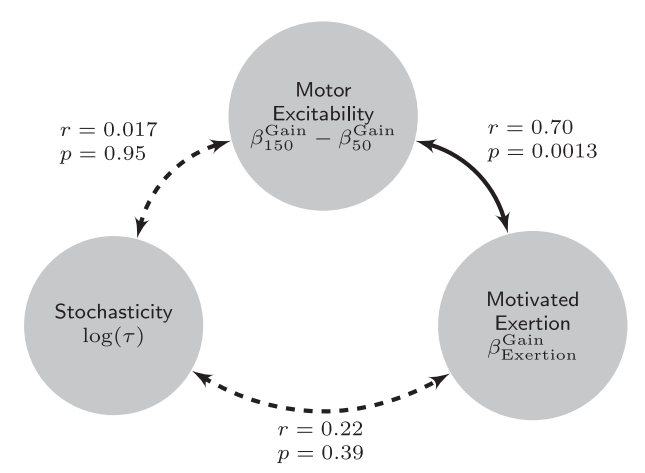

Figure 7. Alternative relationships between choice parameters motor excitability and performance. We also explored the possibility of mediation relationships between choices parameters, obtained from the subjective reward preference task, related to $(\boldsymbol{A})$ risk aversion $-\log (\rho)$ and $(\boldsymbol{B})$ choice stochasticity $\log (\tau)$. These alternative models did not contain the significant correlations required to test whether motor cortical sensitivity to incentive mediated the relationship between performance and these other choice parameters.

\section{Discussion}

In this study, we show that incentive-motivated performance emerges from the temporal dynamics of motor cortical sensitivity to incentive, and that this signature of motor cortical activity reflects an individual's subjective preferences for incentive and eventual behavioral performance. Our neural findings are consistent with previous results in humans showing that appetitive stimuli serve to increase motor cortical excitability (Chiu et al., 2014; Freeman et al., 2014) and that the dynamics of motor cortical excitability is sensitive to the value of options presented during simple choice (Klein-Flügge and Bestmann, 2012). Furthermore, our results align with nonhuman primate studies, which found that motor cortical activity increased in response to cues predicting receipt of reward (Marsh et al., 2015; Ramkumar et al., 2016; Ramakrishnan et al., 2017). However, as previous studies either investigated instrumental responding or valuebased choice in separate paradigms, they did not examine the relationship between the temporal dynamics of motor cortical sensitivity to incentive, subjective preferences for incentive, and eventual motor performance. Our results go beyond these studies by separately characterizing the temporal dynamics of motor cortical sensitivity to incentive and subjective preferences for incentive, and further, modeling the causal relationship between these independent measures and behavioral performance. In so doing, we demonstrate a mechanism by which motor cortical activity mediates the relationship between subjective preferences for incentive and incentive-motivated performance. These results suggest that an individual's subjective preferences for incentive modulate the vigor of the motor system to drive incentivemotivated performance.

We previously used functional imaging to show that, when performing an instrumental motor task for incentive, prospective incentives are first encoded as a potential gain; and subsequently, during the task itself, individuals encode the potential loss that would arise from failure (Chib et al., 2012, 2014). This reframed loss encoding served to motivate behavioral performance: those individuals that were more loss averse had a greater behavioral sensitivity to incentive, such that they reached peak performance at lower incentive levels. Moreover, we found that activity in the ventral striatum, a region of the brain thought to serve as the interface between motivation and motor performance (Mogenson et al., 1980; Bray et al., 2008; Talmi et al., 2008), was predictive of both performance and loss aversion. Notably, ventral striatal reward circuitry is widely implicated in motivated performance (Adcock et al., 2006; Pessiglione et al., 2006; Clithero et al., 2011; Liljeholm and O'Doherty, 2012; Schmidt et al., 2012). Consistent with our previous results, here we found that behavioral sensitivity to incentive in the gain domain was related to an individual's loss aversion. Those individuals that were more loss averse had increased behavioral sensitivity to incentive, suggesting that they were more motivated for increasing incentives. The temporal dynamics of motor cortical sensitivity to incentive also reflected an individual's behavioral loss aversion: those individuals that were more loss averse showed an increasing motor cortical sensitivity to incentive closer to movement onset. These new TMS results take our previous reframing interpretation further and show that motivational constructs (i.e., loss aversion), known to be encoded by reward regions of the brain, transfer to motor areas (as reflected by motor cortical excitability changes), giving rise to motivated behavioral performance.

The present results provide important new insights into how incentive motivational processing influences motor cortical activity to give rise to performance. One possible mechanistic account of our findings relates to the role of the ventral striatum as a limbic-motor interface, mediating interactions between systems for Pavlovian valuation and motoric instrumental responding (Mogenson et al., 1980; Alexander and Crutcher, 1990; Cardinal et al., 2002; Balleine and Ostlund, 2007). Whereas previous literature has focused on the role of the ventral striatum in mediating the effect of reward-predicting cues in increasing or enhancing instrumental performance for reward, less is known about how such reward processing influences activity in motor cortex to give rise to behavioral performance. An elegant set of studies used a Pavlovian instrumental transfer paradigm to study such effects, and showed that appetitive cues served to increase motor cortical excitability during instrumental responding in extinction (Chiu et al., 2014; Freeman et al., 2014). In our experiment, it is possible that during motor performance the prospect of reward (and loss-aversion induced motivation) elicits participants' Pavlovian conditioned responses. These responses could include motor approach and engagement of attentional or orienting mechanisms toward task performance. Such ventral striatal encoding of Pavlovian responses could energize the motor cortical commands necessary for successful execution of instrumental responses, and this motor energization could manifest in the motor cortical sensitivities to incentive that we observe in our 
data. Accordingly, there are strong direct and indirect connections between ventral striatal regions known to encode such Pavlovian and reward values and motor cortex (Mogenson et al., 1980; Haber and Knutson, 2010).

Further supporting these ideas about the motor cortex was a mediation analysis showing that motor cortical sensitivity to incentive mediated the effects of behavioral loss aversion on performance. This mediation suggests that the motor cortex is not merely indirectly correlated with performance through its relationship with loss aversion, but instead plays a critical role in moderating incentive-motivated behavioral performance itself. This provides a mechanistic account of how the motor cortex influences motivated motor performance via its reflection of subjective preferences and incentive value.

A number of studies have reported that performance-based incentives can lead to paradoxical effects on behavior, that is, decreasing motivation (Gneezy and Rustichini, 2000) or performance (Ariely et al., 2009), yet here we examined the case in which performance-based incentives lead to increases in motoric output. The effects of reward undermining and other paradoxical effects on performance have implicated the same ventral striatal reward circuitry that is responsible for the facilitatory effects of incentives on performance (Murayama et al., 2010; Chib et al., 2012, 2014). Therefore, it is plausible that similar motor cortical responses to those identified in this study could be responsible for mediating other paradoxical responses to incentive. Investigating such a role of motor cortical excitability on other effects of performance-based incentives will be an important future direction in dissecting the general motor cortical signals that influence both facilitatory and deleterious influences of incentives on performance.

Given the likely role of ventral striatal reward processing in the context of our task, an alternative account of our results is that the motor cortical stimulation in our experiment could remotely induce responses in the striatum that cause the incentive motivational effects we observed. Previous brain stimulation studies have shown that repetitive TMS of PFC (Strafella et al., 2001) and motor cortex (Strafella et al., 2003), and transcranial direct current stimulation of PFC (Chib et al., 2013), can remotely induce changes in striatal and midbrain activity. However, such an interpretation of our results seems unlikely given that these studies used montages that required a sustained stimulation of cortex to alter its resting state, whereas we used a single-pulse paradigm in which pulses are less likely to result in prolonged changes in motor cortical excitability.

It is important to note, although we found a significant modulation of behavioral performance for increasing prospective loss, we failed to find such an effect in motor cortical excitability responses. Notably, a previous study that examined how aversive conditioned stimuli influenced motor cortical excitability, during instrumental responding, also failed to find a modulation of motor cortical excitability by aversive stimuli (Chiu et al., 2014). One interpretation of these null results is that distinct neural circuits could process the effects of appetitive and aversive stimuli on motivated motor performance (Pessiglione and Delgado, 2015). Indeed, distinct amygdala nuclei have been shown to encode appetitive (basolateral amygdala) (Holland et al., 2002) and aversive (central nuclei) (Petrovich et al., 2009) stimuli during motivated behavior. These amygdala nuclei are essential components in the circuits that mediate Pavlovian instrumental transfer and have different circuit pathways that connect to ventral striatum to influence motivated performance (Cador et al., 1989; Corbit et al., 2001; Lingawi and Balleine, 2012). However, it is not known whether these pathways also have different connections to the motor cortex. It is possible that such differential TMS effects could be the result of such distinct pathways for appetitive and aversive stimuli. Resolving this possibility is beyond the design of the current study and could be achieved using functional neuroimaging techniques, combined with noninvasive brain stimulation, to examine how motor cortical excitability is related to amygdala and ventral striatal function in the context of motor performance for prospective gains and losses.

Integrating behavioral analysis of motivated performance, modeling of subjective preferences for incentive, and motor cortical physiology, we provide evidence that the motor cortex is sensitive to the subjective value of incentive. Our work outlines a mechanism by which the subjective value of reward serves to invigorate motor cortical excitability, leading to incentivemotivated performance. Far from simply being a reflection of motor output, it appears that motor cortical physiology integrates cognitive mechanisms related to reward valuation. These results suggest that incentive-motivated performance is the reflection of an interaction between reward valuation and motor cortical excitability.

\section{References}

Adcock RA, Thangavel A, Whitfield-Gabrieli S, Knutson B, Gabrieli JD (2006) Reward-motivated learning: mesolimbic activation precedes memory formation. Neuron 50:507-517. CrossRef Medline

Ahn WY, Haines N, Zhang L (2017) Revealing neurocomputational mechanisms of reinforcement learning and decision-making with the hBayesDM package. Comput Psychiatry 1:24-57. CrossRef Medline

Alexander GE, Crutcher MD (1990) Functional architecture of basal ganglia circuits: neural substrates of parallel processing. Trends Neurosci 13:266271. CrossRef Medline

Ariely D, Bracha A, Meier S (2009) Doing good or doing well? Image motivation and monetary incentives in behaving prosocially. Am Econ Rev 99:544-555. CrossRef

Balleine BW, Ostlund SB (2007) Still at the choice-point. Ann N Y Acad Sci 1104:147-171. CrossRef Medline

Berridge KC (2004) Motivation concepts in behavioral neuroscience. Physiol Behav 81:179-209. CrossRef Medline

Betancourt M, Girolami M (2015) Hamiltonian Monte Carlo for hierarchical models. In: Current Trends in Bayesian Methodology with Applications, pp 79-101. New York: Chapman and Hall/CRC.

Bindra D (1974) A motivational view of learning, performance, and behavior modification. Psychol Rev 81:199-213. CrossRef Medline

Bolles RC (1972) Reinforcement, expectancy, and learning. Psychol Rev 79: 394-409. CrossRef

Bolles RC, Fanselow MS (1980) PDR: a multi-level model of fear and pain. Behav Brain Sci 3:315-323. CrossRef

Brainard DH (1997) The psychophysics toolbox. Spat Vis 10:433-436. CrossRef Medline

Bray S, Rangel A, Shimojo S, Balleine B, O’Doherty JP (2008) The neural mechanisms underlying the influence of pavlovian cues on human decision making. J Neurosci 28:5861-5866. CrossRef Medline

Cador M, Robbins TW, Everitt BJ (1989) Involvement of the amygdala in stimulus-reward associations: interaction with the ventral striatum. Neuroscience 30:77-86. CrossRef Medline

Cardinal RN, Parkinson JA, Hall J, Everitt BJ (2002) Emotion and motivation: the role of the amygdala, ventral striatum, and prefrontal cortex. Neurosci Biobehav Rev 26:321-352. CrossRef Medline

Chen R, Hallett M (1999) The time course of changes in motor cortex excitability associated with voluntary movement. Can J Neurol Sci 26:163169. CrossRef Medline

Chib VS, De Martino B, Shimojo S, O’Doherty JP (2012) Neural mechanisms underlying paradoxical performance for monetary incentives are driven by loss aversion. Neuron 74:582-594. CrossRef Medline

Chib VS, Yun K, Takahashi H, Shimojo S (2013) Noninvasive remote activation of the ventral midbrain by transcranial direct current stimulation of prefrontal cortex. Transl Psychiatry 3:e268. CrossRef Medline

Chib VS, Shimojo S, O'Doherty JP (2014) The effects of incentive framing 
on performance decrements for large monetary outcomes: behavioral and neural mechanisms. J Neurosci 34:14833-14844. CrossRef Medline

Chiu YC, Cools R, Aron AR (2014) Opposing effects of appetitive and aversive cues on Go/No-go behavior and motor excitability. J Cogn Neurosci 26:1851-1860. CrossRef Medline

Clithero JA, Reeck C, Carter RM, Smith DV, Huettel SA (2011) Nucleus accumbens mediates relative motivation for rewards in the absence of choice. Front Hum Neurosci 5:87. CrossRef Medline

Corbit LH, Muir JL, Balleine BW (2001) The role of the nucleus accumbens in instrumental conditioning: evidence of a functional dissociation between accumbens core and shell. J Neurosci 21:3251-3260. CrossRef Medline

Duque J, Ivry RB (2009) Role of corticospinal suppression during motor preparation. Cereb Cortex 19:2013-2024. CrossRef Medline

Freeman SM, Aron AR (2016) Withholding a reward-driven action: studies of the rise and fall of motor activation and the effect of cognitive depletion. J Cogn Neurosci 28:237-251. CrossRef Medline

Freeman SM, Razhas I, Aron AR (2014) Top-down response suppression mitigates action tendencies triggered by a motivating stimulus. Curr Biol 24:212-216. CrossRef Medline

Frydman C, Camerer C, Bossaerts P, Rangel A (2011) MAOA-L carriers are better at making optimal financial decisions under risk. Proc R Soc Lond B Biol Sci 278:2053-2059. CrossRef Medline

Gneezy U, Rustichini A (2000) A fine is a price. J Legal Stud 29:1-17. CrossRef

Haber SN, Knutson B (2010) The reward circuit: linking primate anatomy and human imaging. Neuropsychopharmacology 35:4-26. CrossRef Medline

Holland PC, Petrovich GD, Gallagher M (2002) The effects of amygdala lesions on conditioned stimulus-potentiated eating in rats. Physiol Behav 76:117-129. CrossRef Medline

Hortobágyi T, Mieras A, Rothwell J, Del Olmo MF (2017) Dissociation between behavior and motor cortical excitability before and during ballistic wrist flexion and extension in young and old adults. PLoS One 12: e0186585. CrossRef Medline

Judd CM, Kenny DA (1981) Process analysis: estimating mediation in treatment evaluations. Eval Rev 5:602-619. CrossRef

Klein PA, Olivier E, Duque J (2012) Influence of reward on corticospinal excitability during movement preparation. J Neurosci 32:18124-18136. CrossRef Medline

Kleiner M, Brainard D, Pelli D, Ingling A, Murray R, Broussard C (2007) What's new in psychtoolbox-3. Perception 36:1-16. CrossRef Medline

Klein-Flügge MC, Bestmann S (2012) Time-dependent changes in human corticospinal excitability reveal value-based competition for action during decision processing. J Neurosci 32:8373-8382. CrossRef Medline

Klein-Flügge MC, Nobbs D, Pitcher JB, Bestmann S (2013) Variability of human corticospinal excitability tracks the state of action preparation. J Neurosci 33:5564-5572. CrossRef Medline

Kurniawan IT, Seymour B, Talmi D, Yoshida W, Chater N, Dolan RJ (2010) Choosing to make an effort: the role of striatum in signaling physical effort of a chosen action. J Neurophysiol 104:313-321. CrossRef Medline

Leocani L, Cohen LG, Wassermann EM, Ikoma K, Hallett M (2000) Human corticospinal excitability evaluated with transcranial magnetic stimulation during different reaction time paradigms. Brain 123:1161-1173. CrossRef Medline

Liljeholm M, O’Doherty JP (2012) Contributions of the striatum to learning, motivation, and performance: an associative account. Trends Cogn Sci 16:467-475. CrossRef Medline

Lingawi NW, Balleine BW (2012) Amygdala central nucleus interacts with dorsolateral striatum to regulate the acquisition of habits. J Neurosci 32:1073-1081. CrossRef Medline

Marsh BT, Tarigoppula VS, Chen C, Francis JT (2015) Toward an autonomous brain machine interface: integrating sensorimotor reward modulation and reinforcement learning. J Neurosci 35:7374-7387. CrossRef Medline

Mogenson GJ, Jones DL, Yim CY (1980) From motivation to action: functional interface between the limbic system and the motor system. Prog Neurobiol 14:69-97. CrossRef Medline

Murayama K, Matsumoto M, Izuma K, Matsumoto K (2010) Neural basis of the undermining effect of monetary reward on intrinsic motivation. Proc Natl Acad Sci U S A 107:20911-20916. CrossRef Medline

Pascual-Leone A, Valls-Solé J, Wassermann EM, Hallett M (1994) Responses to rapid-rate transcranial magnetic stimulation of the human motor cortex. Brain J Neurol 117):847-858. CrossRef

Pessiglione M, Delgado MR (2015) The good, the bad and the brain: neural correlates of appetitive and aversive values underlying decision making. Curr Opin Behav Sci 5:78-84. CrossRef

Pessiglione M, Seymour B, Flandin G, Dolan RJ, Frith CD (2006) Dopamine-dependent prediction errors underpin reward-seeking behaviour in humans. Nature 442:1042-1045. CrossRef Medline

Pessiglione M, Schmidt L, Draganski B, Kalisch R, Lau H, Dolan RJ, Frith CD (2007) How the brain translates money into force: a neuroimaging study of subliminal motivation. Science 316:904-906. CrossRef Medline

Petrovich GD, Ross CA, Mody P, Holland PC, Gallagher M (2009) Central, but not basolateral, amygdala is critical for control of feeding by aversive learned cues. J Neurosci 29:15205-15212. CrossRef Medline

Pitcher D, Walsh V, Yovel G, Duchaine B (2007) TMS evidence for the involvement of the right occipital face area in early face processing. Curr Biol 17:1568-1573. CrossRef Medline

Pitcher D, Goldhaber T, Duchaine B, Walsh V, Kanwisher N (2012) Two critical and functionally distinct stages of face and body perception. J Neurosci 32:15877-15885. CrossRef Medline

Preacher KJ, Hayes AF (2004) SPSS and SAS procedures for estimating indirect effects in simple mediation models. Behav Res Methods Instrum Comput 36:717-731. CrossRef Medline

Preacher KJ, Kelley K (2011) Effect size measures for mediation models: quantitative strategies for communicating indirect effects. Psychol Methods 16:93-115. CrossRef Medline

Ramakrishnan A, Byun YW, Rand K, Pedersen CE, Lebedev MA, Nicolelis MA (2017) Cortical neurons multiplex reward-related signals along with sensory and motor information. Proc Natl Acad Sci U S A 114: E4841-E4850. CrossRef Medline

Ramkumar P, Dekleva B, Cooler S, Miller L, Kording K (2016) Premotor and motor cortices encode reward. PLoS One 11:e0160851. CrossRef Medline

R Development Core Team (2008) R: a language and environment for statistical computing. Vienna: R Foundation for Statistical Computing.

Rossini PM, Barker AT, Berardelli A, Caramia MD, Caruso G, Cracco RQ, Dimitrijević MR, Hallett M, Katayama Y, Lücking CH (1994) Noninvasive electrical and magnetic stimulation of the brain, spinal cord and roots: basic principles and procedures for routine clinical application. report of an IFCN committee. Electroencephalogr Clin Neurophysiol 91: 79-92. CrossRef Medline

Schmidt L, Lebreton M, Cléry-Melin ML, Daunizeau J, Pessiglione M (2012) Neural mechanisms underlying motivation of mental versus physical effort. PLoS Biol 10:e1001266. CrossRef Medline

Sokol-Hessner P, Hsu M, Curley NG, Delgado MR, Camerer CF, Phelps EA (2009) Thinking like a trader selectively reduces individuals' loss aversion. Proc Natl Acad Sci U S A 106:5035-5040. CrossRef Medline

Stan Development Team (2017) RStan: the R interface to Stan. Retrieved September 11, 2018. http://mc-stan.org.

Staude G, Flachenecker C, Daumer M, Wolf W (2001) Onset detection in surface electromyographic signals: a systematic comparison of methods. EURASIP J Appl Signal Process 2001:67-81.

Stefan K, Wycislo M, Classen J (2004) Modulation of associative human motor cortical plasticity by attention. J Neurophysiol 92:66-72. CrossRef Medline

Strafella AP, Paus T, Barrett J, Dagher A (2001) Repetitive transcranial magnetic stimulation of the human prefrontal cortex induces dopamine release in the caudate nucleus. J Neurosci 21:RC157. CrossRef Medline

Strafella AP, Paus T, Fraraccio M, Dagher A (2003) Striatal dopamine release induced by repetitive transcranial magnetic stimulation of the human motor cortex. Brain 126:2609-2615. CrossRef Medline

Talmi D, Seymour B, Dayan P, Dolan RJ (2008) Human pavlovian instrumental transfer. J Neurosci 28:360-368. CrossRef Medline

Vallence AM, Kurylowicz L, Ridding MC (2013) A comparison of neuroplastic responses to non-invasive brain stimulation protocols and motor learning in healthy adults. Neurosci Lett 549:151-156. CrossRef Medline 